\title{
Jean Cocteau. Les adaptations, textes réunis et présentés par Serge Linares
}

\section{Mireille Brangé}

\section{Q OpenEdition}

\section{Journals}

\section{Édition électronique}

URL : http://journals.openedition.org/studifrancesi/6420

DOI : 10.4000/studifrancesi.6420

ISSN : 2427-5856

Éditeur

Rosenberg \& Sellier

\section{Édition imprimée}

Date de publication : 1 novembre 2010

Pagination : 585-586

ISSN : 0039-2944

\section{Référence électronique}

Mireille Brangé, «Jean Cocteau. Les adaptations, textes réunis et présentés par Serge Linares », Studi Francesi [En ligne], 162 (LIV | III) | 2010, mis en ligne le 30 novembre 2015, consulté le 15 janvier 2021. URL : http://journals.openedition.org/studifrancesi/6420; DOI : https://doi.org/10.4000/studifrancesi. 6420

Ce document a été généré automatiquement le 15 janvier 2021.

\section{(c)}

Studi Francesi è distribuita con Licenza Creative Commons Attribuzione - Non commerciale - Non opere derivate 4.0 Internazionale. 


\title{
Jean Cocteau. Les adaptations, textes réunis et présentés par Serge Linares
}

\author{
Mireille Brangé
}

\section{RÉFÉRENCE}

Jean Cocteau. Les adaptations, textes réunis et présentés par Serge LINARES, Paris, Lettres Modernes Minard, 2008 («La Revue des lettres modernes. Série Jean Cocteau», 5), pp. 191.

1 Ce volume, qui s'attache essentiellement aux adaptations signées par Cocteau, marque la reprise de la série dans le regain de faveur connu par l'auteur durant la dernière décennie. Les perspectives variées des contributions rendent compte d'une pratique dont les occurrences attestent la véritable nécessité intérieure, au-delà des circonstances et d'une «tendance coupable au pastiche» (p. 8). Pour celui qui proclama: «Un article original ne peut pas copier. Il n'a donc qu'à copier pour être original» (Le Coq et l'Arlequin), adapter fut un moyen privilégié pour «vérifier la puissance et la permanence» de son identité tout en se poussant «dans ses retranchements d'écrivain» et en élargissant «le champ de ses possibles» (pp. 8-9), rappelle Serge LiNARES dans son introduction.

2 Côté théâtre, ce dernier (D’après l'antique?, pp. 13-31) expose aussi la complexité de la relation à Sophocle auquel Cocteau s'identifie dès 1912. L'intertexte d'Antigone (1922), d'CEdipe Roi (1925) et de La Machine infernale (1932) permet de nuancer la rupture supposée du Potomak (1919). Il révèle tout le palimpseste des admirations littéraires Anna de Noailles, Maurice Barrès, Joseph Péladan - et théâtrales premières (MounetSully). Cette remontée dans les textes littéraires est donc aussi remontée de l'écrivain dans sa propre psyché, hantée par l'ombre du père et le fantasme incestueux. Pierre 
CAZAiRgues (De "Dear Liar" à “Cher Menteur", pp. 3338) retrace la genèse de l'adaptation de la pièce de Jérôme Kilty (1960) effectuée pour Maria Casarès.

Côté cinéma, une série d'articles parcourt une activité souvent méjugée. Les dialogues des Dames du bois de Boulogne où il doit couler ses mots à la fois dans le texte de Diderot et dans le scénario de Bresson qui prône un souci de "compression» (cité p. 59) et d'«hypervisibilité de l'écriture» (p. 64), révèlent ainsi un Cocteau «instrument [...] du surgissement de la grâce» bressonnienne (p. 68) (Christophe MARTIN, Une parole soufflée, pp. 53-71). Florence NAUGRETTE montre comment Cocteau adaptateur de "Ruy Blas" (pp.91-101) conserve l'«esprit» et le lyrisme de Hugo, sinon sa lettre (le texte est déversifié). Et s'il infléchit le propos politique de la pièce vers le film de cape et d'épée et les questions d'identité et de gémellité, y passent les ombres de l'Occupation encore proche. Solène BERTRAND (“L'Éternel retour", pp. 39-52) montre, au travers des sources de la légende tristanienne utilisées pour le film de Jean Delannoy (1943), comment Cocteau, tout en actualisant le mythe, se place dans le sillage de la réécriture médiévale. Mais la seconde collaboration des deux hommes (1960), étudiée par Angie VAN STEERTHEM (Jean Cocteau collaborateur de Jean Delannoy pour "La Princesse de Clèves", pp.111-129), entachée par leurs différends antérieurs, limite l'influence du poète au dialogue.

4 Étudiant les films réalisés par lui, Maurice MOURIER ("La Belle et la Bête" ou l'enfance de l'art, pp. 73-89) rapproche la technique du film des tressautements de la lanterne magique de La Recherche du temps perdu et des trucs du premier cinéma, témoignage de confiance de Cocteau dans l'enfance de l'art pour atteindre la féerie. Danielle CHAPERON étudie parallèlement, au prisme de la «théâtralité» et des analyses d'André Bazin, "Les Parents terribles" et "L'Aigle à deux têtes" au cinéma (pp.131-148), deux adaptations contemporaines (1948) aux partis-pris et à la réception diamétralement opposés.

La réflexion se poursuit, sur d'autres plans, dans la section des mélanges. Dans la relation critique réciproque d'Artaud (acteur et critique d'Antigone en 1922) et de Cocteau (critique de l'adaptation du Moine de Lewis en 1931), étudiée par Olivier PENOTLACASSAGNE («Une sorte de sorcellerie verbale», pp. 115-165), c'est en effet de traduction et d'adaptation qu'il s'agit encore et d'un autoportrait, quand Cocteau écrit: «Les forts ne peuvent pas traduire» (cité p. 158). La critique du Sang d'un poète (1932), dans laquelle Artaud le renvoie dos à dos avec les Surréalistes marque la fin de cette conversation. Moncef NABLI ("Judith et Holopherne" de Jean Cocteau, pp. 167-178) s'attache à l'adaptation picturale de l'épisode de la décollation d'Holopherne par Judith (1948).

Par ailleurs François RougET (Jean Cocteau correcteur de ses vers, pp. 179-189) propose les transcriptions de poèmes de jeunesse inédits du fonds Koch (Yale). Une bibliographie indicative complète le dossier. 